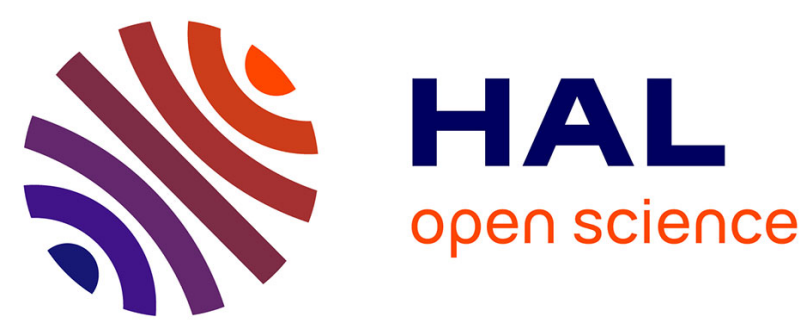

\title{
Thermal degradation and fire behavior of thermoset resins modified with phosphorus containing styrene
}

Lucie Tibiletti, Laurent Ferry, Claire Longuet, André Mas, Jean-Jacques Robin, José-Marie Lopez-Cuesta

\section{- To cite this version:}

Lucie Tibiletti, Laurent Ferry, Claire Longuet, André Mas, Jean-Jacques Robin, et al.. Thermal degradation and fire behavior of thermoset resins modified with phosphorus containing styrene. Polymer Degradation and Stability, 2012, 97 (12), pp.2602-2610. 10.1016/j.polymdegradstab.2012.01.032 . hal-00930059

\section{HAL Id: hal-00930059 \\ https://hal.science/hal-00930059}

Submitted on 9 Jul 2021

HAL is a multi-disciplinary open access archive for the deposit and dissemination of scientific research documents, whether they are published or not. The documents may come from teaching and research institutions in France or abroad, or from public or private research centers.
L'archive ouverte pluridisciplinaire HAL, est destinée au dépôt et à la diffusion de documents scientifiques de niveau recherche, publiés ou non, émanant des établissements d'enseignement et de recherche français ou étrangers, des laboratoires publics ou privés. 


\title{
Thermal degradation and fire behavior of thermoset resins modified with phosphorus containing styrene
}

\author{
Lucie Tibiletti $^{\mathrm{a}, \mathrm{b}}$, Laurent Ferry ${ }^{\mathrm{a}, *}$, Claire Longuet $^{\mathrm{a}}$, André Mas ${ }^{\mathrm{b}}$, Jean-Jacques Robin ${ }^{\mathrm{b}}$, \\ José-Marie Lopez-Cuesta ${ }^{a}$ \\ ${ }^{a}$ Centre des Matériaux de Grande Diffusion, Ecole des Mines d'Alès, 6 Avenue de Clavières, 30319 Alès Cedex, France

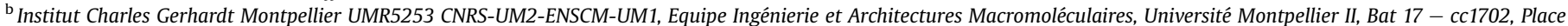 \\ Eugène Bataillon, 34095 Montpellier Cedex 5, France
}

\section{A B S T R A C T}

In order to improve the fire behavior of unsaturated polyester resins (UPR) a phosphorus containing monomer, dimethyl-vinylbenzyl phosphonate (or S1), was used to replace a part of the reactive diluent (styrene). UPR with various phosphorus contents were prepared. Thermal degradation was studied using thermogravimetric analysis (TGA) and pyrolysis combustion flow microcalorimeter (PCFC), while fire behavior was investigated by cone calorimeter. The phosphorus yield in the residue was determined using energy-dispersive X-ray (EDX).

TGA pointed out a decrease in thermal stability with increasing S1 content but also an important increase in char formation. Cone calorimetry highlighted pHRR decrease, and from $50 \%$ of styrene substitution a barrier effect was evidenced. Residue analysis enabled to determine the partition of phosphorus between vapor and condensed phase. It was shown that this partition depends on the degree of styrene substitution. At high S1 content, interactions between phosphonate groups enable a very efficient condensed phase action by creation of a charred protective barrier. This strategy was also successfully transposed to a vinyl ester resin (VER).

Keywords:

Unsaturated polyester

Thermal stability

Cone calorimetry

Phosphonated monomer

\section{Introduction}

Unsaturated polyesters (UPR) and vinyl ester resins (VER), used since the 50's, belong to the huge panel of commercially available thermoset polymers. Due to their low cost, their numerous applications include among others construction and building materials, marine and ship, automotive, railway, tanks and containers, electronic devices... [1]. Hence improved thermal stability and fire reaction are required for these materials, in order to ensure the safety of goods and people. For instance, the new EU standard for fire protection on railway vehicles, EN 45545 , replaces all the national classification, and requires low hazard levels of flame spread, heat release, smoke opacity and toxicity.

The current commercial solutions include halogenated polyester resins, and ATH filled UPR [2]. An interesting alternative is the use of phosphorous flame retardants. They can be used either as additive or as reactive compounds. In this study, the efficiency of phosphorus grafted onto the polymeric matrix was tested. Grafting

\footnotetext{
* Corresponding author. Tel.: +3346678 53 58; fax: +3346678 5365 . E-mail address: Laurent.Ferry@mines-ales.fr (L. Ferry).
}

phosphorus on a polymer backbone is possible according to two routes: by modifying the chain after the polymerization, as it has been achieved in various polymer matrices, like polyethylene [3] and polystyrene $[4,5]$, or by modifying the monomers used for the synthesis. This strategy has been tested in thermoplastics such as polymethylmethacrylate [6], polyesters [7] or polyurethanes [8] but is less developed in thermoset polymers, except maybe for epoxy resins [9]. Only few attempts to graft phosphorus on UPR have been described in the literature $[10,11,12]$.

As UPR are two-component based polymers, it is possible to modify either the pre-polymer (i.e. the monomers used for the polycondensation), or the reactive diluent. This latter solution is attractive because it could be applied to a wide range of polyesters without changing the polycondensation process. In this work, the reactive diluent (styrene) was partially or totally substituted by the dimethyl-vinylbenzylphosphonate monomer. Thermal stability as well as flammability of the phosphonated modified UPR were characterized and compared to those of the unmodified resin. A particular attention was paid to the action mode of phosphonate species. Finally, the use of the phosphonated styrenic monomer was extended to a vinyl ester resin in order to demonstrate the interest of this flame retardant strategy. 


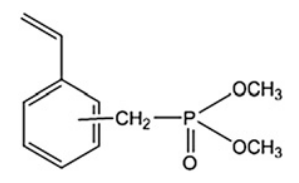

Scheme 1. Chemical structure of dimethyl-vinylbenzylphosphonate (S1).

\section{Experimental}

\subsection{Materials}

Orthophthalic based unsaturated polyester (commercial name Aropol G174-2), with a styrene content of 38wt.\% was kindly supplied by Ashland Polyester. The corresponding pre-polymer (i.e. the polyester without styrene) was also supplied.

The phosphorus containing monomer used in this study, dimethyl-vinylbenzylphosphonate, is presented in Scheme 1. Its synthesis has been described in details elsewhere [13].

A schematic representation of a phosphonated resin is proposed in Scheme 2.
Table 1

Composition and phosphorus amount of the S1 containing resins.

\begin{tabular}{lllll}
\hline $\begin{array}{l}\text { Sample } \\
\text { name }\end{array}$ & $\begin{array}{l}\text { Modified } \\
\text { monomer }\end{array}$ & $\begin{array}{l}\text { wt.\% of modified } \\
\text { monomer }\end{array}$ & $\begin{array}{l}\text { wt.\% of } \\
\text { styrene }\end{array}$ & $\begin{array}{l}\text { wt.\% of } \\
\text { phosphorus }\end{array}$ \\
\hline Pure resin & $/$ & $/$ & $/$ & $/$ \\
$0.25 \mathrm{~S} 1$ & S1 & 9.5 & 29.5 & 1.3 \\
$0.5 \mathrm{~S} 1$ & $\mathrm{~S} 1$ & 19 & 19 & 2.6 \\
$1.0 \mathrm{~S} 1$ & $\mathrm{~S} 1$ & 38 & 0 & 5.2 \\
\hline
\end{tabular}

\subsection{Samples preparation}

The pre-polymer was diluted with mixtures of styrene and S1. The amount of S1 in each mixture was varied, in order to get various global amounts of phosphorus in the samples (Table 1). Since the viscosity of the pre-polymer at room temperature was too high to enable its mixing with styrene and S1, it was previously heated in an oven at $100{ }^{\circ} \mathrm{C}$. After adding the required amount of catalyst (cobalt octoate) and initiator (methyl ethyl ketone peroxide or MEEKP), the samples were then cast in glass moulds and cured at room temperature and finally post cured at $60{ }^{\circ} \mathrm{C}$ for $8 \mathrm{~h}$ and at $100{ }^{\circ} \mathrm{C}$ for $2 \mathrm{~h}$. A reference sample (named pure resin)

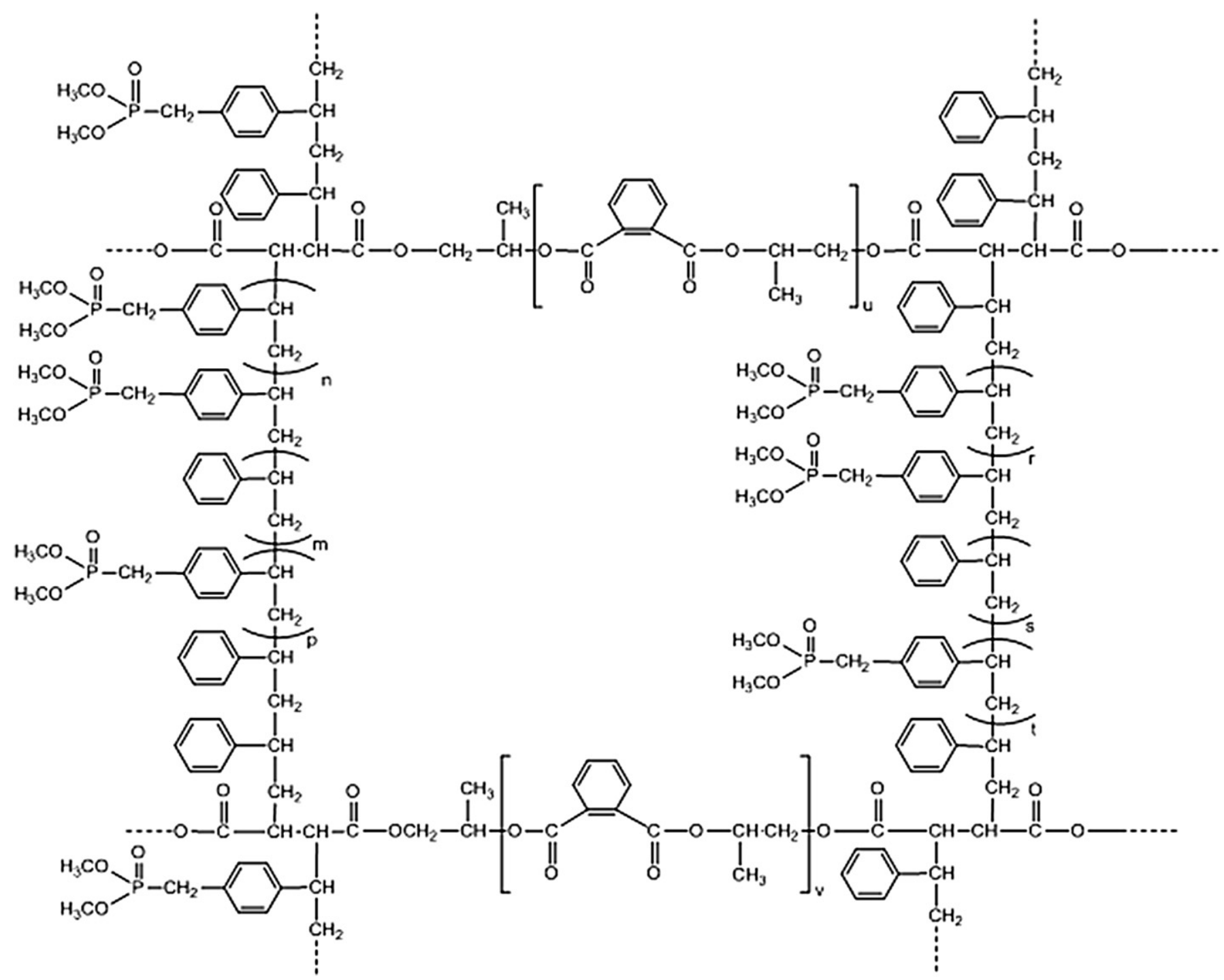

Scheme 2. Schematic representation of an unsaturated polyester modified with S1. 

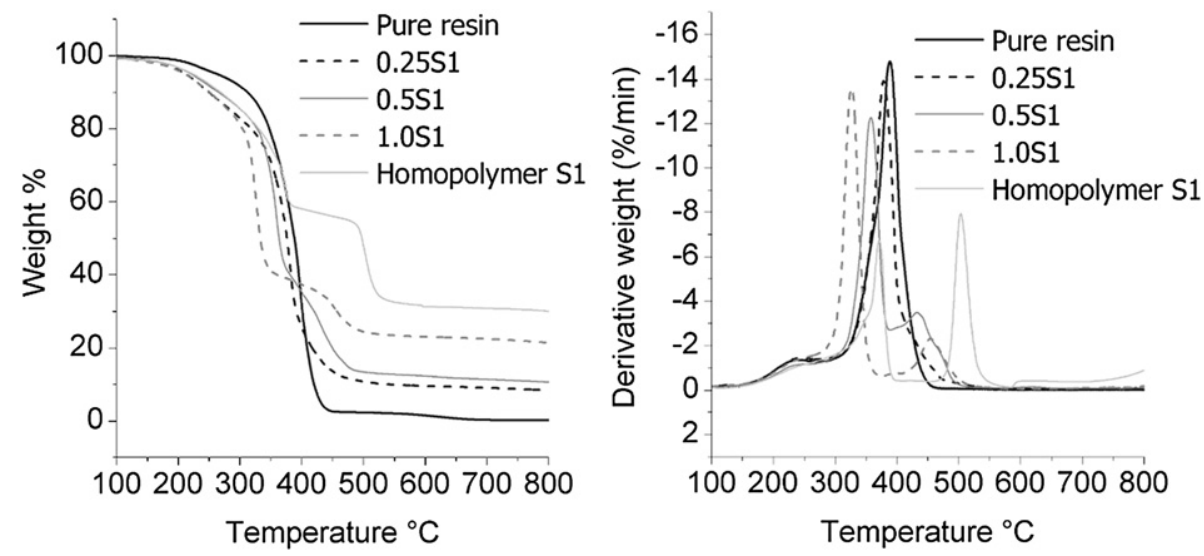

Fig. 1. TG and DTG curves for unsaturated polyester modified with S1, and for poly(dimethyl-vinylbenzylphosphonate).

with pure styrene as reactive diluent was also prepared as a reference.

\subsection{Methods}

TGA was performed using a Perkin Elmer Pyris-1 TGA thermobalance, controlled by the Pyris software. For each sample, two runs were carried out at a heating rate of $10{ }^{\circ} \mathrm{C} / \mathrm{min}$ from room temperature to $800{ }^{\circ} \mathrm{C}$ under a nitrogen flow of $20 \mathrm{~mL} / \mathrm{min}$. Reported data are $T_{2 \%}, T_{5 \%}, T_{10 \%}$ i.e. the temperatures at which the resin displays respectively 2,5 and 10 wt.\% weight loss, Tdm i.e. the temperature at which the degradation rate is the highest, and the residue amount at $800{ }^{\circ} \mathrm{C}$.

Fire behavior of the resins was investigated using a pyrolysis combustion flow calorimeter (PCFC). In this technique initially developed by Lyon, Walter and co-workers at the Federal Aviation Administration laboratories [14]. The specimen, whose mass is about $2 \pm 0.5 \mathrm{mg}$ is first heated at $1{ }^{\circ} \mathrm{C} / \mathrm{s}$ from $100{ }^{\circ} \mathrm{C}$ to $750{ }^{\circ} \mathrm{C}$ in a pyrolyzer and the degradation products are transported by an inert gas flux, and then mixed with oxygen before entering in a combustor at $900{ }^{\circ} \mathrm{C}$ where the decomposition products are totally oxidized. For this technique, Heat Release Rate (HRR), peak of Heat Release Rate (pHRR) values are measured as a function of temperature and the calculations are based on the Principle of Huggett. HRC (heat release capacity) is defined as pHRR/heating rate.

Cone calorimetry is one of the most efficient polymer fire behavior bench scale tests. The principle of the cone calorimeter experiments is based on the measurement of the oxygen concentration decrease in the combustion gases of a sample subjected to a given heat flux. The sample $\left(100 \times 100 \times 4 \mathrm{~mm}^{3}\right)$ is placed on the microbalance support that enables following the evolution of the mass loss during the experiment. All experiences were carried out at a $35 \mathrm{~kW} / \mathrm{m}^{2}$ irradiance. From the measurement of the gas flow and of the oxygen concentration, the quantity of heat released per unit of time and surface is calculated: HRR (Heat Released Rate) expressed in $\mathrm{kW} / \mathrm{m}^{2}$. This parameter and the value of its maximum (pHRR or peak of Heat Release Rate) are usually taken into account for the evaluation of the fire behavior of materials. Data reported are the average of two runs. pHRR data are reproducible within $\pm 5 \%$. The cone calorimeter of the laboratory was supplied by Fire Testing Technology company.

A scanning electron microscope (FEI Quanta 200 SEM) was used to study the morphology of the residues. Images were obtained under high vacuum at a voltage of $15.0 \mathrm{kV}$. Analysis of the phosphorus percentage in residues was carried out by EDX using Oxford
INCA Energy 300 and a detector of $133 \mathrm{eV}$ resolution (at Mn). The residues obtained after cone calorimeter tests were crushed in a mortar and compressed with a microscope glass for forming a compact and smooth layer before analysis.

DMTA tests were performed using a Metravib VA815 between room temperature and $160{ }^{\circ} \mathrm{C}$ at a heating rate of $1{ }^{\circ} \mathrm{C} / \mathrm{min}$. $30 * 10 * 4 \mathrm{~mm}^{3}$ samples were tested in traction-compression mode at a frequency of $5 \mathrm{~Hz}$, evolution of the storage modulus as well as the loss factor were recorded.

Solubility tests were performed in chloroform: a small amount of each sample (i.e. between 3 and $5 \mathrm{~g}$ ) was crushed and introduced in a flask with $100 \mathrm{~mL}$ of chloroform under stirring for about $20 \mathrm{~h}$. The resulting mixtures were filtered; the filtrate was dried in an oven overnight at $120^{\circ} \mathrm{C}$ then weighed to determine the fraction of material which was not soluble.

\section{Results and discussion}

\subsection{Thermal stability}

Fig. 1 displays the TGA curve of the pure UPR and the resins modified with S1. The decomposition of the pure resin includes two steps. A first small weight loss occurs at $250{ }^{\circ} \mathrm{C}$ that was attributed in the literature either to a dehydration [15], or to a loss of phthalic anhydride [16]. Then, the main step occurs around $400{ }^{\circ} \mathrm{C}$ corresponding to the chain scission of polyester and polystyrene fragments.

The introduction of a phosphonated styrenic monomer has dramatic consequences on the thermal stability of the UPR, since TGA curves are shifted to lower temperatures (Fig. 1 ). $T_{2 \%}, T_{5 \%}$ and $T_{10 \%}$ are decreased for all the phosphonated samples (Table 2 ). This effect was also reported in PS and in PMMA modified with phosphorus containing methacrylates $[17,18]$, or in copolymers of

Table 2

Characteristic temperatures of degradation and residues amounts from TGA experiments for unsaturated polyester modified with S1 and for poly(dimethylvinylbenzylphosphonate).

\begin{tabular}{lccccc}
\hline Sample & $T_{2} \%$ & $T_{5} \%$ & $T_{10} \%$ & $T \mathrm{dm}$ & $\begin{array}{r}\text { Residues } \\
@ 800{ }^{\circ} \mathrm{C}\end{array}$ \\
\hline Pure resin & 216 & 262 & 312 & 388 & 0.2 \\
$0.25 \mathrm{~S} 1$ & 165 & 212 & 250 & 378 & 8.3 \\
$0.5 \mathrm{~S} 1$ & 175 & 220 & 265 & 358 & 10.5 \\
1.0 S1 & 159 & 211 & 250 & 326 & 21.3 \\
Homopolymer S1 & 173 & 223 & 268 & 503 & 29.8 \\
\hline
\end{tabular}




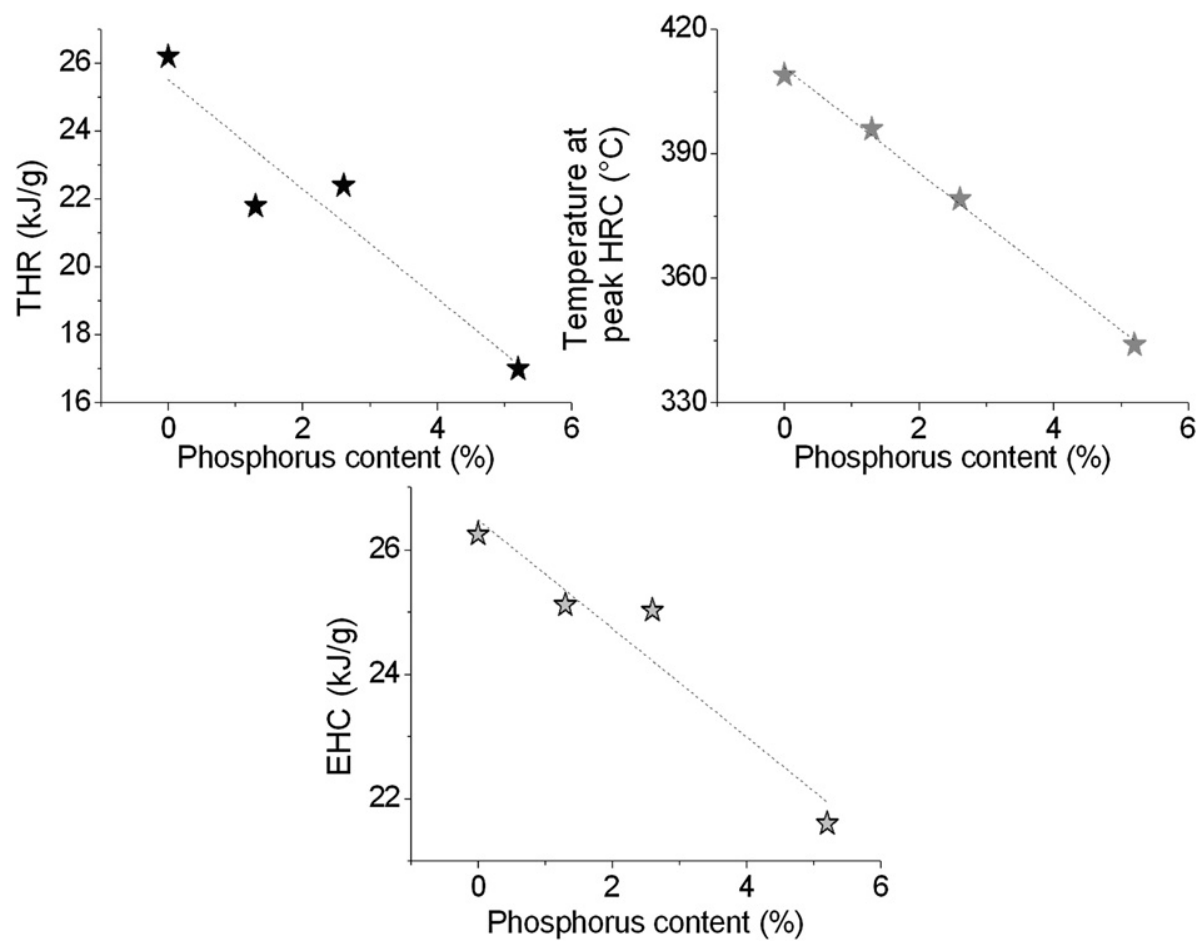

Fig. 2. Evolution of the PCFC characteristic values in function of the sample phosphorus content.

acrylonitrile and dialkyl-vinylbenzylphosphonate [19]. This early degradation will be discussed later on (§3.5).

A first decomposition stage has been ascribed to the degradation of the phosphorous groups, either by homolytic break due to the fragility of the C-P bond [20], or by loss of the alkyl chain of the phosphonate group $[17,19]$. In the first decomposition stage, the resin degradation leads to the release of high flammable species (alcohol, ketones... [20]) that increase the degradation rate. But once a charred structure starts to form thanks to the phosphorus acting in the condensed phase, it behaves as a protective layer for the polymer, slowing down the decomposition.

It seems interesting to compare the thermal stability of the phosphonated polyester resins with that of the homopolymer of S1 that was presented in a previous study [21]. The degradation of poly(dimethyl-vinylbenzylphosphonate) was described as follows: the first stage between 210 and $400{ }^{\circ} \mathrm{C}$ was attributed to the $\mathrm{CH}_{3}$ loss from the $\left(\mathrm{P}-\mathrm{O}-\mathrm{CH}_{3}\right)$ groups and to the polymer backbone $\left(\mathrm{CH}-\mathrm{CH}_{2}\right)$ decomposition, and the second stage between 400 and $540{ }^{\circ} \mathrm{C}$ was ascribed to the loss of aromatic groups. It was suggested that residues were due to the formation of $\mathrm{P}-\mathrm{O}-\mathrm{P}$ bonds by intramolecular condensation [21].1.0S1 and to a lesser extent 0.5S1 have degradation pathways similar to that of the homopolymer, except that they are shifted to lower temperatures. Therefore, the presence of a plateau between 400 and $500{ }^{\circ} \mathrm{C}$ could be attributed to the presence of $\mathrm{S} 1$, but not the decrease of the thermal stability, since the main degradation temperature is approximately similar to that of the pure resin.

Table 3

Characteristic values from PCFC experiments for the phosphorous containing unsaturated polyesters.

\begin{tabular}{llll}
\hline Sample (unit) & HRC $(\mathrm{J} /(\mathrm{g} . \mathrm{K}))$ & THR $(\mathrm{kJ} / \mathrm{g})$ & $T_{\text {peak }}\left({ }^{\circ} \mathrm{C}\right)$ \\
\hline Pure resin & 416 & 26.2 & 409 \\
$0.25 \mathrm{~S} 1$ & 392 & 21.8 & 396 \\
$0.5 \mathrm{~S} 1$ & 357 & 22.4 & 379 \\
$1.0 \mathrm{~S} 1$ & 420 & 17 & 344 \\
\hline
\end{tabular}

The introduction of phosphonated styrene S1 also enhances the charring phenomenon. The residue amount is found very high, considering that the reactive diluent represents only $38 \mathrm{wt} . \%$ of the material. The early degradation of the phosphorous groups accelerates the decomposition at relatively low temperatures and in a second step the carbonaceous layer limits the release of flammable species. Concerning $0.25 \mathrm{~S} 1$ composition, it can be assumed that as the phosphorus amount is low, the probability for two phosphonate groups to condense is low, and then an effective barrier would not be created prior to the resin decomposition.

\subsection{PCFC analysis}

In accordance with TGA measurements, analyses carried out with PCFC show a decrease of the degradation temperature with increasing styrene substitution for $\mathrm{S} 1$ containing resins, as confirmed by the shift of HRC peak $\left(T_{\text {peak }}\right)$ toward low temperatures (Fig. 2).

Table 3 indicates that HRC as well as THR decrease with increasing S1 content (an unexplained result is obtained for 1S1 HRC). Moreover, THR decrease is almost proportional to the phosphorus content as revealed by Fig. 2. To determine whether this decrease is due to condensed phase action or both condensed and vapor phase action, the effective heat of combustion (EHC) was calculated by dividing the THR by the weight loss obtained by TGA at $750{ }^{\circ} \mathrm{C}$. The results (Fig. 2) indicate that EHC decreases with increasing phosphorus content. Therefore, a vapor phase action is evidenced. Since flame inhibition due to phosphorus cannot be assessed by PCFC, this effect could be related to fuel dilution by the less combustible phosphorous species.

\subsection{Cone calorimeter analysis}

Pure UPR is a material that burns almost totally. The charring is limited with a very low final amount of residues (1.5\%). Fig. 3 

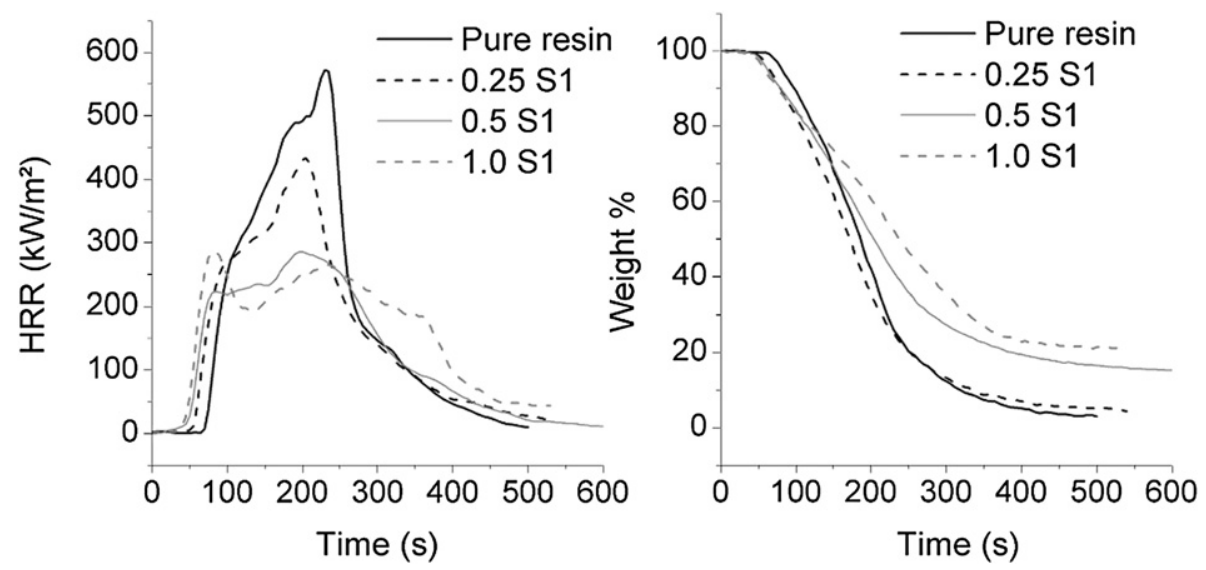

Fig. 3. HRR (left) and residual mass (right) versus time for the UPR modified with S1.

Table 4

Cone calorimeter data of the S1 containing UPR.

\begin{tabular}{lllllll}
\hline & TTI s & $\begin{array}{l}\text { HRR } \\
\mathrm{kW} / \mathrm{m}^{2}\end{array}$ & $\begin{array}{l}\mathrm{pHRR} \\
\mathrm{kW} / \mathrm{m}^{2}\end{array}$ & $\begin{array}{l}\text { THR } \\
\mathrm{MJ} / \mathrm{m}^{2}\end{array}$ & $\begin{array}{l}\text { Residues } \\
\%\end{array}$ & $\begin{array}{l}\text { EHC } \\
\mathrm{MJ} / \mathrm{kg}\end{array}$ \\
\hline Pure resin & 59 & 202 & 592 & 89 & 1.5 & 19.6 \\
$0.25 S 1$ & 57 & 164 & 433 & 81 & 4.2 & 17.2 \\
0.5S1 & 42 & 148 & 309 & 74 & 14.5 & 17.2 \\
$1.0 \mathrm{~S} 1$ & 34 & 129 & 301 & 81 & 22.5 & 25.2 \\
\hline
\end{tabular}

shows that the HRR curve for the pure resin is characteristic of a non charring material [22]. The pHRR value of $592 \mathrm{~kW} / \mathrm{m}^{2}$ is reached in the second part of the combustion process. The THR of the pure resin combustion is $89 \mathrm{MJ} / \mathrm{m}^{2}$, with an ignition time of $59 \mathrm{~s}$.

According to Table 4, there is a decrease of the time to ignition for all samples containing S1. This may be correlated to the lower thermal stability as highlighted by TGA. This can show that S1 starts to decompose before the resin does, which could mean that it is available for reaction when the polymer is degrading and volatilizing. 0.5S1 and 1.0S1 have close fire behaviors. Their HRR curves exhibit a particular shape where HRR rises first to a maximum value and then exhibits a short plateau or decreases. The peak of HRR is reduced by almost 50\% compared to the pure resin. Besides, a decrease of the mass loss rate is also observed. This behavior is typical of the formation of a protective charred layer at the surface of the sample. Plotting the cumulative THR as a function of mass loss enables to determine the EHC of gases which corresponds to the slope of the curve (Fig. 4). All the curves are close to that of the unmodified resin. There is a slight decrease for low substitution degrees $(0.25 \mathrm{~S} 1$ and $0.5 \mathrm{~S} 1)$ indicating a gas phase action but for higher substitution (1.0S1) no gas phase action is evidenced.

Fig. 4 also shows that the residue amount increases proportionally to the phosphorus content. This residue represents more than $20 \%$ for complete styrene substitution. Furthermore, in the presence of phosphorus, the residues exhibit an expanded structure as highlighted in Fig. 5. Therefore, from all these observations, it can be concluded that the presence of dimethylvinylbenzylphosphonate induces mainly a condensed phase action with a barrier effect.

\subsection{Residue analysis}

The residues of combustion after cone calorimeter test were analyzed by EDX spectroscopy, and it was possible to determine quantitatively their phosphorus content.

Fig. 6 shows that the phosphorus content in the residue increases with increasing degree of styrene substitution, but not proportionally to the initial phosphorus content in the resin.
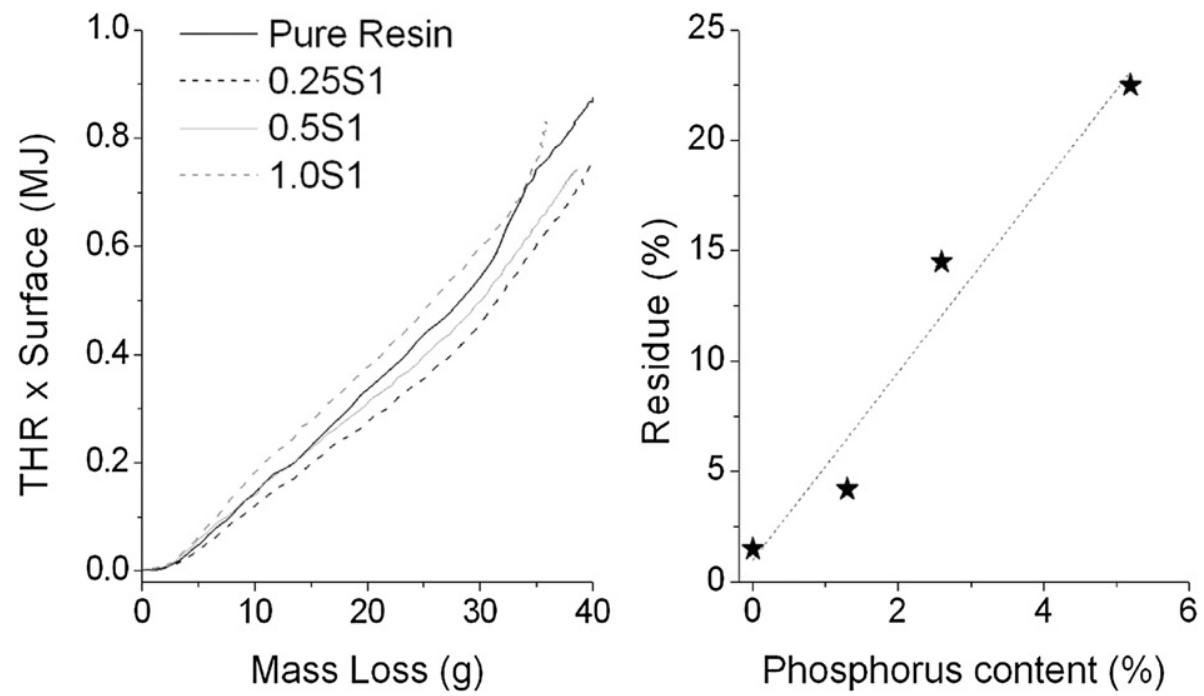

Fig. 4. Comparison of the EHC (slope of the curve on the left) for the S1 containing resins and evolution of the residue amount in function of the phosphorus content. 


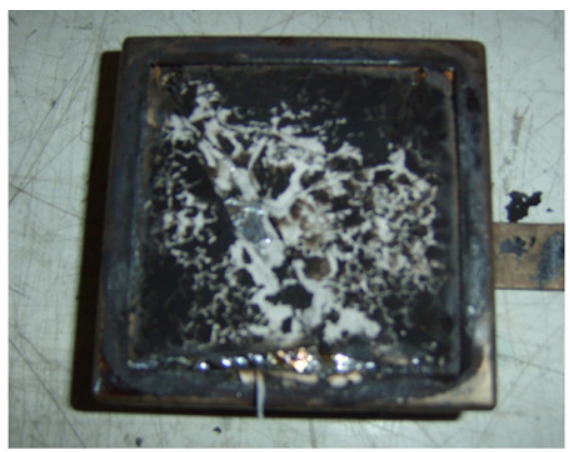

\section{Pure Resin}

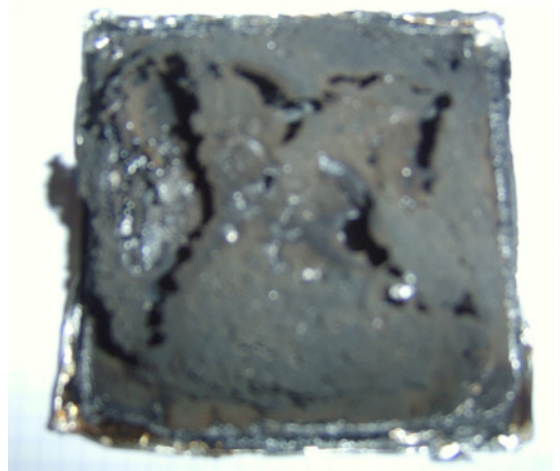

$1.0 \mathrm{~S} 1$

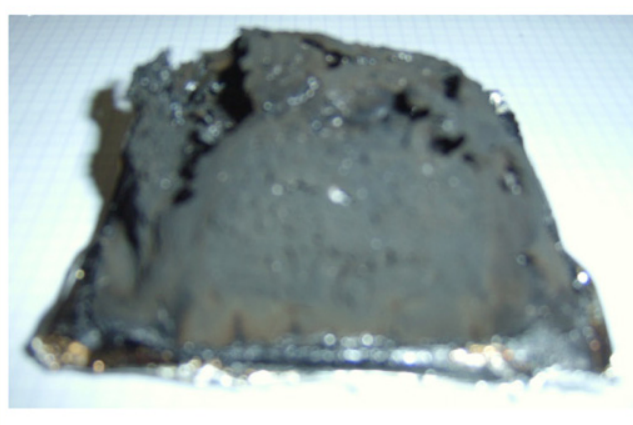

$1.0 \mathrm{~S} 1$

Fig. 5. Residue aspect of the pure resin and 1.0S1.

Knowing the initial phosphorus content $\left(P_{\text {initial }}\right)$, the phosphorus fraction in the residue ( $\left.P_{\text {residue }}\right)$ and the amount of residue (residue \%), the partition of phosphorus between condensed or gas phase was calculated:

$$
\begin{aligned}
P_{\text {condensed_phase }} & =\frac{P_{\text {residue }}{ }^{*} \text { residue } \%}{P_{\text {initial }}} P_{\text {gas_phase }} \\
& =1-P_{\text {condensed_phase }}
\end{aligned}
$$

At low degree of substitution (0.25S1), phosphorus is mainly released in the gas phase whereas for higher degree of substitution, it remains mainly in the condensed phase (Fig. 6). It is thought that the proportion of phosphorus in the condensed phase strongly depends on interaction or reaction between phosphonate groups. Therefore, if the degree of substitution is low there are only few interactions and the residue is low. From a certain degree of substitution, interactions increase and so does the residue amount.
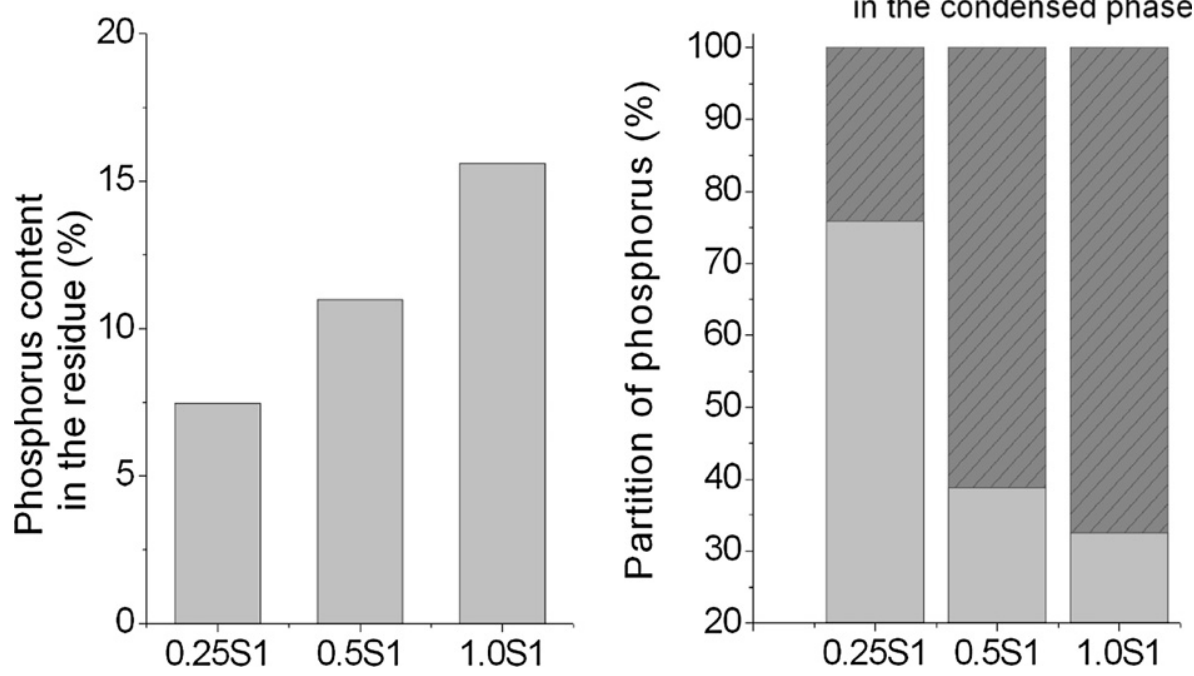

Fig. 6. Amount of phosphorus in the cone calorimeter residues, and its partition according to its mode of action. 

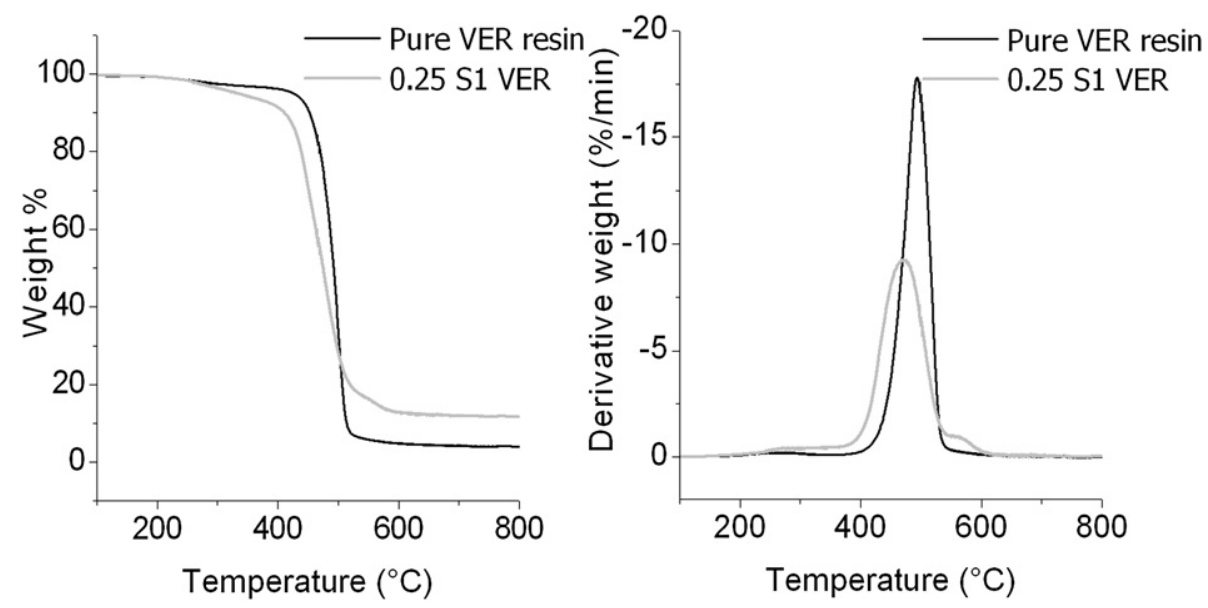

Fig. 7. Characteristic temperatures of degradation and residues amounts from TGA experiments for S1 containing VER.

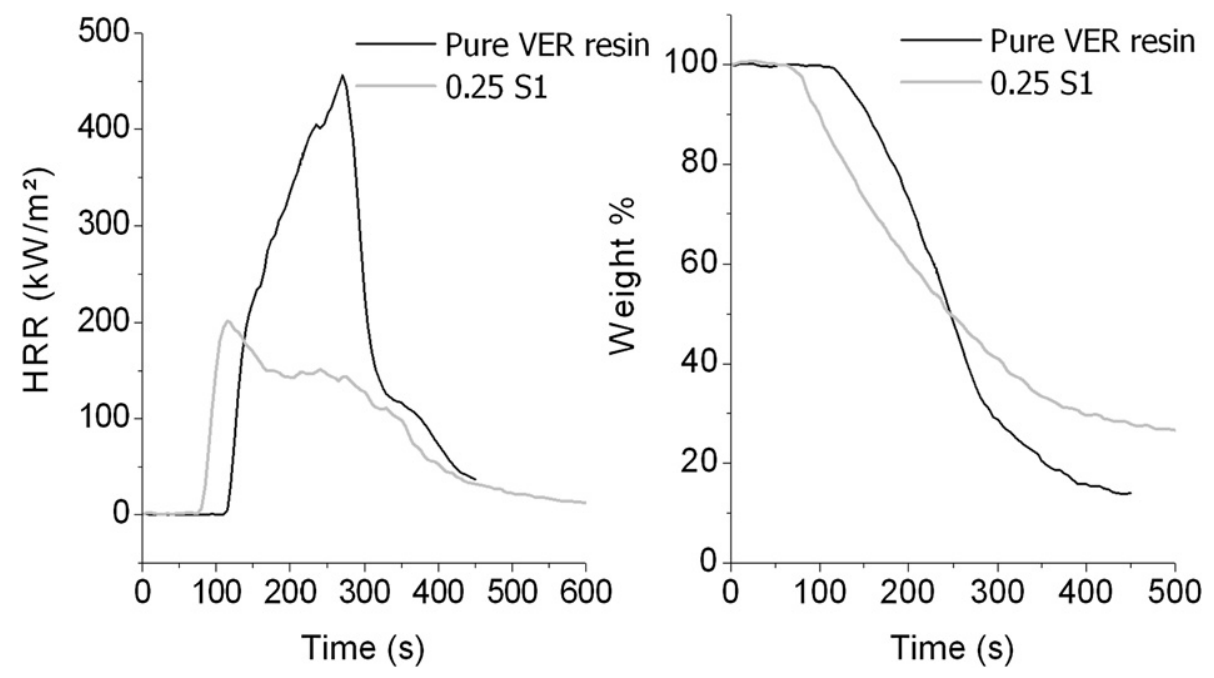

Fig. 8. HRR (left) and residual mass (right) versus time for the S1 containing VER.

\subsection{Crosslinking study}

Decreased thermal stability (decrease of $T_{2} \%$ and shift of the curve toward low temperatures), and reduced times to ignition have been highlighted as negative consequences of the introduction of S1 in the thermoset matrix. Impaired thermal stabilities have already been described in the literature when various phosphonated monomers were grafted on diverse polymer matrices [9,17]. It can be considered that this effect is directly linked to the decomposition pathway of the phosphonated moieties. Nevertheless, in the present case, a softening of the modified unsaturated polyester was also observed. It was thus decided to assess the crosslinking degree of the phosphonated polyester.

From solubility tests in chloroform, the insoluble parts of the resins were determined to be respectively of $96 \pm 4 \%$ for the pure
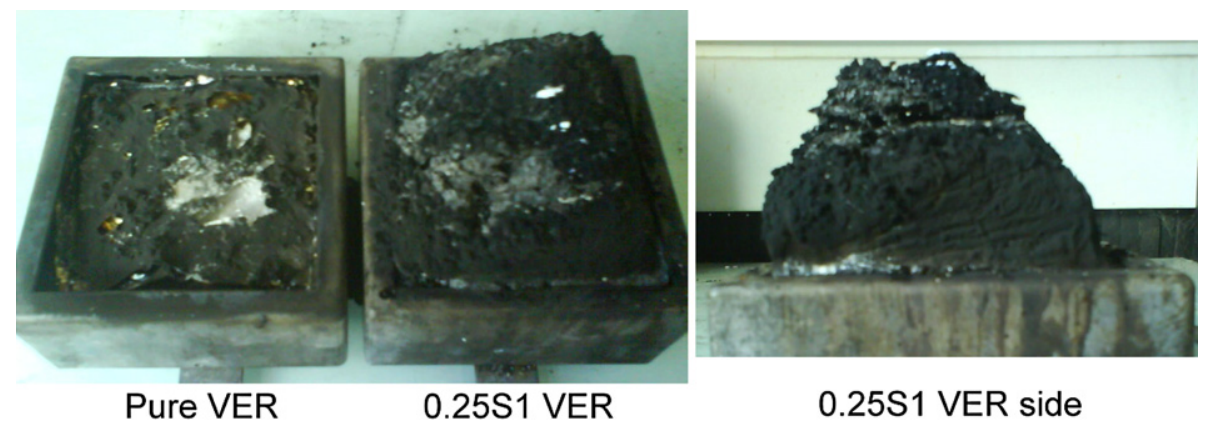

Fig. 9. Residue aspect of the VER. 

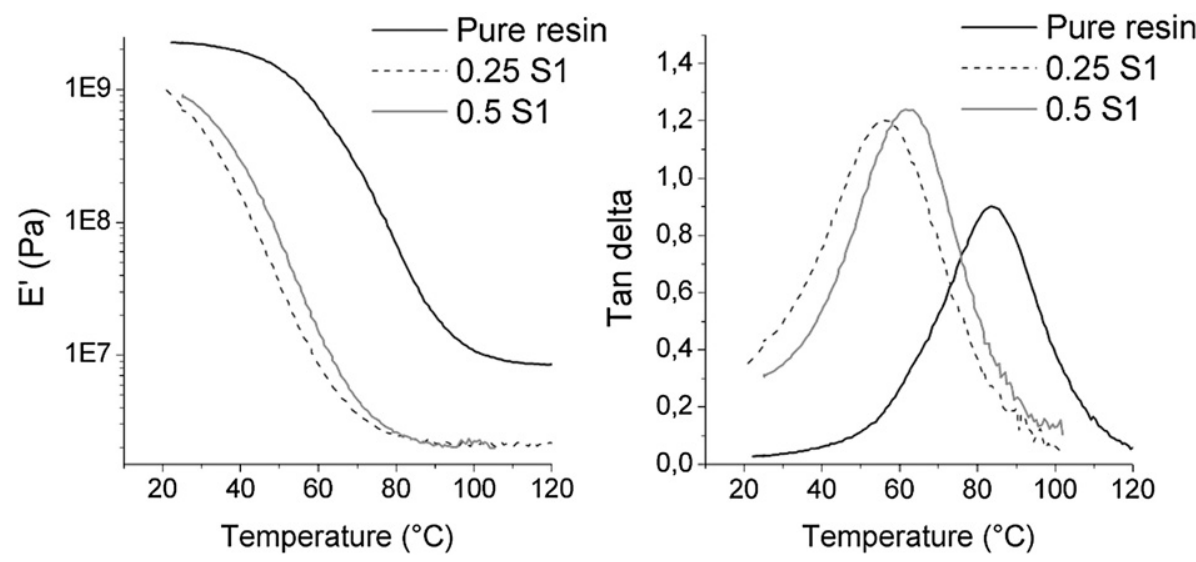

Fig. 10. Variation of the storage modulus $\mathrm{E}^{\prime}$ and tan delta for the modified resins from DMTA analysis.

resin, $71 \pm 5 \%$ for $0.25 \mathrm{~S} 1$ and $63 \pm 4 \%$ for $1 \mathrm{~S} 1$. Hence the solubility increases with the substitution degree. The ${ }^{1} \mathrm{H}$ NMR analysis of the soluble parts revealed that they contain unpolymerized monomers (styrene or S1) as well as polyester oligomers.

To confirm these results, DMTA was also carried out on some of the modified resins (Fig. 10).

When modified monomers are introduced in the polymer matrix, there is an important decrease of the glass transition temperature, as revealed by the decrease of the temperature at the maximum value of tan delta. In addition, the rubbery modulus decreases, which indicates that they act unfavorably on the final network density and lead to materials with decreased stiffness at high temperatures.

It was thus thought that the studied resins are not totally crosslinked. This incomplete crosslinking was presently not fully understood, while it has certainly a negative impact on the fire behavior.

\subsection{Transposition to vinyl ester resin}

Considering the interesting fire reaction obtained with S1 containing UP resin, it was thought to apply the same strategy to another kind of thermoset resin, i.e. a vinyl ester resin. In order to limit concerns related to reactivity between the phosphonated monomer and the prepolymer, a $25 \%$ substitution of styrene was chosen.

The replacement of $25 \%$ styrene decreases the thermal stability of the VER resin (Fig. 7 and Table 5). $T_{2 \%}$ is decreased of $12{ }^{\circ} \mathrm{C}$ and up to $80 \%$ weight loss the curve is shifted to low temperatures. However, from $500{ }^{\circ} \mathrm{C}, \mathrm{S} 1$ induces a stabilization that is pointed out by an important decrease of the degradation rate. The same way of action than in the UP resin may be proposed, and both decomposition steps are merged due to a low amount of phosphorus.

Concerning flame retardancy, the HRR curve for pure VER was very steep with a high peak value, and then decreases rapidly (Fig. 8 and Table 6). The shape corresponds to a non charring material, despite the high value of the residue amount (14\%). The HRR for the

Table 5

Characteristic temperatures of degradation and residues amount from TGA experiments for S1 containing VER.

\begin{tabular}{lccccc}
\hline Sample & $T_{2} \%$ & $T_{5} \%$ & $T_{10} \%$ & $T \mathrm{dm}$ & $\begin{array}{c}\text { Residues } \\
@ 800{ }^{\circ} \mathrm{C}\end{array}$ \\
\hline VER & 269 & 425 & 453 & 494 & 4 \\
$0.25 \mathrm{~S} 1$ & 257 & 331 & 411 & 475 & 11.7 \\
\hline
\end{tabular}

Table 6

Cone calorimeter data of the S1 containing VER.

\begin{tabular}{lclllll}
\hline & TTI $\mathrm{s}$ & $\begin{array}{l}\mathrm{HRR} \\
\mathrm{kW} / \mathrm{m}^{2}\end{array}$ & $\begin{array}{l}\mathrm{pHRR} \\
\mathrm{kW} / \mathrm{m}^{2}\end{array}$ & $\begin{array}{l}\text { THR } \\
\mathrm{MJ} / \mathrm{m}^{2}\end{array}$ & $\begin{array}{l}\text { Residues } \\
\%\end{array}$ & $\begin{array}{l}\text { EHC } \\
\mathrm{MJ} / \mathrm{kg}\end{array}$ \\
\hline VER & 110 & 211 & 456 & 72 & 14 & 18.9 \\
0.25S1 VER & 75 & 88 & 201 & 46 & 25.2 & 13.8 \\
\hline
\end{tabular}

modified VER also reaches its peak in the first part of the combustion, but its value is $50 \%$ that of the pure VER. The corresponding curve is characteristic of a sample forming residues [22]. Once one effective char is formed, it goes on thickening and the HRR decreases until the combustion flames out. S1 increases the residue amount up to $25 \%$, and leads to the formation of an intumescent layer for the residues, proving its role in the condensed phase (Fig. 9). In addition S1 induces a strong EHC reduction meaning that it also can play a role in the vapor phase, but it was much more limited in the case of the UP resin. The addition of S1, except for the reduced TTI, is thus an efficient way to reduce the flammability of vinyl ester resin.

\section{Conclusions}

The influence of a phosphonated monomer (dimethyl-vinylbenzylphosphonate or S1) on the thermal stability and the fire behavior of an unsaturated polyester resin was discussed. Samples with different phosphorus contents were prepared. On the whole, increasing S1 content induces a decrease of the thermal stability of the polymer matrix. The onset degradation temperatures are reduced, curves are shifted to low temperatures, but still charring is increased up to $20 \%$. The early degradation of the phosphonated species first accelerates the resin decomposition but then entails the formation of a charred residue. Concerning fire behavior, it was shown that S1 monomer generates a reduction in pHRR and an increase of the residue amount up to $22 \%$. From $50 \%$ of styrene substitution, S1 induces the formation of a protective layer that acts as a barrier that reduces the evolution of flammable species. It was highlighted that the flame retardant mode of action depends on the phosphorus content. The partition of phosphorus between vapor and condensed phase was thought to be related to interactions between neighboring phosphonate groups. Therefore, high S1 contents favor phosphonate interactions and thus a condensed phase action. Decreased times to ignition, and a softening of the resins were also observed, and were attributed to an incomplete crosslinking. It can be expected that a complete polymerization of the thermoset network (achieved by heating, or by using different 
catalysts) could further improve the fire reaction of these materials, and their mechanical properties. Finally, it was demonstrated that monomer S1 can be used in the same manner and with the same effects on flammability by substituting styrene diluent in a vinyl ester resin.

\section{Acknowledgments}

We would like to thank Ashland Polyester for financial support, Dr Claire Negrell-Guirao for TGA data of poly(dimethylvinylbenzylphosphonate), and $M$. Jean-Marie Taulemesse for SEM/EDX analysis.

\section{References}

[1] Goodman SH. Handbook of thermoset plastics. 2nd ed. Noyes publications; 1999.

[2] Weil ED, Levchik SV. Commercial flame retardancy of unsaturated polyester and vinyl resins: review. Journal of Fire Sciences 2004;22(4):293-303.

[3] Schroeder JP, Sopchak WP. The reaction of phosphorus trichloride and oxygen with polymers. Journal of Polymer Science 1960;47(149):417-33.

[4] Sun J, Cabasso I. Correlation between the degree of phosphorylation of pol$\mathrm{y}$ (styrenephosphonate ester) and its blends with cellulose acetate. Macromolecules 1991;24(12):3603-11.

[5] Sun J, Cabasso I. Impact of degree of phosphorylation on intrinsic and thermal properties of poly(styrenephosphonate diethyl ester)s. Journal of Polymer Science Part A: Polymer Chemistry 1989;27(12):3985-99.

[6] Vahabi H, Longuet C, Ferry L, David G, Robin J-J, Lopez-Cuesta J-M. Effect of aminobisphosphonated copolymer on the thermal stability and flammability of poly(methylmethacrylate). Polymer International 2011. accepted manuscript.

[7] Levchik S, Weil ED. Flame retardancy of thermoplastic polyesters - a review of the recent literature. Polymer International 2005;54(1):11-35.

[8] Levchik SV, Weil ED. Thermal decomposition, combustion and fire-retardancy of polyurethanes $-\mathrm{A}$ review of the recent literature. Polymer International 2004:53(11):1585-610.
[9] Liu YL. Flame-retardant epoxy resins from novel phosphorus-containing novolac. Polymer 2001;42(8):3445-54.

[10] Kuan J-F, Lin K- F. Synthesis of hexa-allylamino-cyclotriphosphazene as a reactive fire retardant for unsaturated polyesters. Journal of Applied Polymer Science 2004;91(2):697-702.

[11] Zhang C, Liu S-M, Huang JY, Zhao J- Q. The synthesis and Flame retardance of a high phosphorus-containing unsaturated polyester resin. Chemistry Letter 2010;39:1270-2.

[12] Zhang C, Huang JY, Liu SM, Zhao JQ. The synthesis and properties of a reactive flame-retardant unsaturated polyester resin from a phosphorus-containing diacid. Polymers for Advanced Technologies 2010.

[13] Boutevin B, Hervaud Y, Boulahna A, Hadrami EME. Synthesis of phosphonated styrenic copolymers and their chemical modifications. Polymer International 2002;51(5):450-7.

[14] Lyon RE, Walters RN. Pyrolysis combustion flow calorimetry. Journal of Analytical and Applied Pyrolysis 2004;71(1):27-46.

[15] Kandare E, Kandola BK, Price D, Nazaré S, Horrocks RA. Study of the thermal decomposition of flame-retarded unsaturated polyester resins by thermogravimetric analysis and Py-GC/MS. Polymer Degradation and Stability 2008 93(11):1996-2006.

[16] Tibiletti L, Longuet C, Ferry L, Coutelen P, Mas A, Robin J-J, et al. Therma degradation and fire behaviour of unsaturated polyesters filled with metallic oxides. Polymer Degradation and Stability 2011;96(1):67-75.

[17] Price D, Cunliffe LK, Bullett KJ, Hull TR, Milnes GJ, Ebdon JR, et al. Thermal behaviour of covalently bonded phosphate and phosphonate flame retardant polystyrene systems. Polymer Degradation and Stability 2007;92(6):1101-14

[18] Price D, Pyrah K, Hull TR, Milnes GJ, Ebdon JR, Hunt BJ, et al. Flame retarding poly(methyl methacrylate) with phosphorus-containing compounds: comparison of an additive with a reactive approach. Polymer Degradation and Stability 2001;74(3):441-7.

[19] Wyman P, Crook V, Ebdon J, Hunt B, Joseph P. Flame-retarding effects of dialkyl-p-vinylbenzyl phosphonates in copolymers with acrylonitrile. Polymer International 2006;55(7):764-71.

[20] Gentilhomme A, Cochez M, Ferriol M, Oget N, Mieloszynski JL. Thermal degradation of methyl methacrylate polymers functionalized by phosphoruscontaining molecules-II: initial flame retardance and mechanistic studies. Polymer Degradation and Stability 2003;82(2):347-55.

[21] Négrell-Guirao C., 2010. Synthesis and flame behaviour of allylic phosphonated (co)polymers or telomers, PhD thesis, University of Montpellier.

[22] Schartel B, Hull TR. Development of fire-retarded materials - Interpretation of cone calorimeter data. Fire and Materials 2007;31(5):327-54. 